\title{
AS PESSOAS CURTEM OS POLITICOS NO FACEBOOK? NÃO MESMO! A COMUNICAÇÃO DIRETA EM LARGA ESCALA ENTRE CANDIDATOS E ELEITORES COMO UM FENÔMENO OUTLIER*1
}

\author{
Rasmus Kleis Nielsen ${ }^{2}$ \\ Cristian Vaccari ${ }^{3}$
}

\begin{abstract}
Resumo
A popularidade online de alguns poucos candidatos tem levado muitos analistas a sugerir que as mídias sociais têm dado aos políticos novas e poderosas formas de se comunicarem diretamente com os eleitores. Examinando se isso está acontecendo em uma escala significativa com base na análise de 224 candidatos dos maiores partidos concorrendo em distritos competitivos para a Câmara dos Deputados dos Estados Unidos durante as eleições parlamentares de 2010, descobrimos que a maioria dos políticos online é, de fato, largamente ignorada pelo eleitorado. A atenção dada pelos cidadãos aos candidatos online se aproxima das distribuições de lei de potência, com alguns candidatos obtendo muitos seguidores e a maioria definhando na obscuridade. Como a comunicação direta online em larga escala entre os políticos e as pessoas comuns nestas plataformas é um fenômeno raro e outlier - mesmo no caso de campanhas eleitorais altamente competitivas e com candidatos com amplo acesso a recursos financeiros - sugerimos, neste texto, que as implicações políticas mais relevantes das mídias sociais assumem a forma de (a) novos fóruns para comunicação indireta sobre política e (b) mudanças institucionais nos processos de comunicação política.
\end{abstract}

\begin{abstract}
The online popularity of a few exceptional candidates has led many to suggest that social media have given politicians powerful new ways of communicating directly with voters. Examining whether this is happening on a significant scale, we find that, based on analysis of 224 major party candidates running in competitive districts for the U.S. House of Representatives during the 2010 congressional elections, most politicians online are, in fact, largely ignored by the electorate. Citizens' attention to candidates online approximates power-law distributions, with a few drawing many followers and most languishing in obscurity. Because large-scale direct online communication between politicians and ordinary people via these platforms is a rare, outlier phenomenon-even in the case of high-stakes, well-resourced campaigns-we suggest that the most relevant political implications of social media take the form of (a) new forums for indirect communication about politics and (b) institutional changes in political communication processes.
\end{abstract}

\footnotetext{
* Artigo originalmente publicado em inglês na International Journal of Communication, n. 7 (2013) pp. 2333-2356, sob o título "Do People "Like" Politicians on Facebook? Not Really. Large-Scale Direct Candidate-to-Voter Online Communication as an Outlier Phenomenon".

O comitê editorial da Revista Eletrônica de Ciência Política agradece aos autores e à University of Southern California Press pela autorização para publicação desta tradução.

Tradução de Márcio Cunha Carlomagno e Sérgio Braga. Supervisão e revisão técnica de Sérgio Braga.

${ }^{1}$ DOI deste artigo: http://dx.doi.org/10.5380/recp.v5i2.41061

${ }^{2}$ Roskilde University. University of Oxford. Contato: rasmuskleisnielsen@gmail.com

${ }^{3}$ Royal Holloway. University of London. University of Bologna. Contato: cristian.vaccari@gmail.com
} 


\section{INTRODUÇÃO}

A espetacular popularidade online de alguns poucos candidatos, tais como Barack Obama e Sarah Palin, tem levado muitos observadores a sugerir que uma nova geração de ferramentas de Internet - e, em particular, sites de mídias sociais cada vez mais populares, como Facebook, Twitter e YouTube - têm dado aos políticos novas e poderosas formas de se comunicarem diretamente com os cidadãos (GOLBECK, GRIMES, \& ROGERS, 2010; GUEORGUIEVA, 2008; IYENGAR, 2011; LASSEN \& BROWN, 2011; NEWMAN, 2010; PAPACHARISSI, 2009). Esta ideia é familiar desde os debates sobre as gerações anteriores de ferramentas da internet, como, por exemplo, websites e e-mails, que supostamente também permitiriam novas formas de comunicação direta entre as elites políticas e cidadãos comuns (por exemplo, COLEMAN \& BLUMLER, 2001). Esta também é uma crença amplamente disseminada por empresas e consultores de mídia social, ansiosos por aproveitar as esperanças e desejos de políticos e de seus assessores, e um cenário temido por alguns jornalistas, receosos de verem seu papel como intermediários da comunicação ser posto em perigo.

A promessa da comunicação direta também parece plausível à luz dos altos níveis de uso da Internet nas democracias pós-industriais, em que o acesso está longe de ser um fator limitante. Vassia Gueorguieva (2008) sugeriu que o surgimento de sites de mídias sociais "criou benefícios tais como o aumento do potencial de exposição do candidato a um custo muito baixo ou nulo, fornecendo aos candidatos menos conhecidos um meio viável para divulgar suas mensagens" (p. 288). Jennifer Golbeck et al. (2010) argumentam que ferramentas como Twitter proporcionam um fórum para "comunicação direta entre congressistas e sua base eleitoral” (p. 1620). Shanto Iyengar (2011) recentemente observou que "o advento da tecnologia de compartilhamento de vídeos e do rápido crescimento do alcance das redes sociais abriram amplas possibilidades para a comunicação direta entre candidato e eleitor" (p. 4). Mas, mesmo com mais candidatos e cidadãos presentes online, isso não implica necessariamente que eles realmente se comuniquem online - e que, portanto, o potencial para a comunicação direta seja atingido. Com efeito, a pré-condição para que isso ocorra é que as pessoas de fato prestem atenção aos políticos no Facebook e em plataformas semelhantes. Conforme procuraremos demonstrar neste artigo, uma análise mais detalhada da presença dos candidatos na web sugere que, na maioria dos casos, isto não está acontecendo. 
Examinaremos neste artigo se a ampla difusão das ferramentas digitais tem, de fato, facilitado uma comunicação online mais extensa e direta entre os políticos e seus potenciais eleitores. Com base na análise da presença na internet (abrangendo sites de campanha, Facebook, Twitter e YouTube) de 224 candidatos, nos 112 distritos mais competitivos das eleições intermediárias de 2010 para a Câmara dos Deputados dos Estados Unidos, observamos que este não é o caso. Embora a maioria dos cidadãos e dos políticos esteja online, eles não estão conectados online. Com efeito, apenas uma pequena minoria de candidatos obtém um número significativo de visitantes em seus websites, apoiadores no Facebook, seguidores no Twitter e espectadores no YouTube. Na verdade, a maioria dos políticos conta com uma audiência online de poucos milhares ou mesmo centenas de internautas. A mediana do número de apoiadores no Facebook, entre os 224 candidatos que compõem a nossa base de dados, é de 1806, e a mediana de seguidores no Twitter é de 365 (os distritos que eles pretendem representar têm uma população média de cerca de 700.000 habitantes). A popularidade online dos candidatos não segue o padrão de uma distribuição normal - com muitos candidatos alcançando um número significativo de indivíduos - mas altamente enviesada, se aproximando das distribuições de lei de potência* encontradas em outros fenômenos online tais como visitas em websites, inbound links e número de downloads (HINDMAN, 2008; RUSSELL, 2011; SHIRKY, 2003). Alguns poucos políticos atraem muita atenção dos internautas, mas a maioria obtém muito pouca desta atenção, o que sugere que a comunicação direta em larga escala entre candidatos e eleitores por meio das mídias sociais é a exceção, não a regra. Essas desigualdades são muitas vezes obscurecidas por resultados de surveys relatando que certa percentagem da população adulta segue políticos no Facebook ou no Twitter ou recebe informações de campanha online (SMITH, 2011A, 2011b).

Argumentamos que a frequentemente negligenciada distribuição real da atenção dos cidadãos à presenca dos candidatos na web tem consequências importantes para a forma como entendemos as implicações políticas de mídias sociais e outras plataformas online para a comunicação política. Porque a maioria das pessoas não "curte" a maioria dos políticos no Facebook, não os segue no Twitter e assim por diante, a comunicação direta em larga escala por meio de sites de mídia social é um fenômeno raro e outlier, algo que acontece apenas em uma pequena minoria de disputas eleitorais, mesmo quando um grande número de pessoas usam estas ferramentas para outros fins. Essa realidade reflete a

\footnotetext{
${ }^{*}$ N. do T.: Lei de potência (no inglês, power law) é a demominação matemática de uma distribuição desigual da ordem $80 \%-20 \%$. Uma das mais célebres leis de potências é o princípio de Pareto.
} 
dinâmica pull゙ de um ambiente de mídia misto e de alta escolha, onde o interesse das pessoas (variável e muitas vezes baixo) em políticos, em particular, é fundamental para compreender se os candidatos conseguem chegar aos cidadãos online (BIMBER \& DAVIS, 2003; NEUMAN, PARK, \& PANEK, 2012; PRIOR, 2007). Nossos achados a este respeito refletem os resultados de pesquisa em outras áreas, tal como política eleitoral (RUSSELL, 2011; SHIRKY, 2003). Em outro momento (VACCARI \& NIELSEN, 2013), usamos modelos de regressão multivariada para identificar os fatores causais por trás destas diferenças e descobrimos que, embora características socioeconômicas em nível distrital provoquem poucos efeitos sobre a popularidade dos candidatos online, desafiantes e candidatos em disputas open-seat tendem a atrair uma maior audiência online, assim como os candidatos que são mais visíveis em blogs políticos. Surpreendentemente, quão intensa é a cobertura dos candidatos pela imprensa, quão populares eles são em pesquisas de opinião e quanto dinheiro eles gastam durante a campanha não produz nenhum efeito significativo. Neste artigo, nos concentramos na análise das características centrais da presença na web dos candidatos ao Congresso nas eleições de 2010 dos EUA e examinamos as implicações conceituais para a forma como entendemos o papel das mídias sociais como parte dos processos de comunicação política.

Adotando uma distinção comum tanto ao marketing quanto aos estudos sobre internet e política, partimos da constatação de que, de maneira similar aos meios digitais anteriores (como sites de campanha), as mídias sociais são primariamente pull media, nas quais as pessoas optam por entrar - ao invés de terem acesso às mensagens involuntariamente. Como Bruce Bimber e Richard Davis (2003, pp. 145-157) argumentaram, o alcance e os efeitos da campanha online são limitados pela natureza "seletiva" da maioria dos ambientes de Internet, que se caracterizam por grandes volumes de informação política, ampla variedade de fontes e muitas opções oferecidas aos usuários. Enquanto a maioria dos eleitores dá pouca atenção aos políticos e apresenta um interesse limitado na política, push media, como a publicidade (incluindo publicidade online), mala direta, prospecção de votos nas ruas e serviços por telefone são meios mais plausíveis para a comunicação direta com os cidadãos. Às vezes, a distinção push/pull é vista como análoga aos "velhos" meios de comunicação (one-way, top-down, de massa) versus "novos" meios de

\footnotetext{
${ }^{*}$ N. do T.: Optamos por conservar as expressões pull e push do original por não possuírem equivalente de uso consagrado e sem ambiguidades em português, além do fato de tais termos, no original, serem recorrentes mesmo na literatura lusófona.

${ }^{*} \mathrm{~N}$. do T.: O termo open-seat designa disputas em que não há um incumbente no cargo concorrendo à reeleição.
} 
comunicação (interativas, descentralizadas, individualizadas) (HOLBERT, GARRETT \& GLEASON, 2010). Mas, parece mais útil ver a distinção como tendo a ver com grandes diferenças entre as formas dominantes de se envolver com diferentes tipos de mídia e conteúdo. Tanto nos estudos sobre marketing quanto nas pesquisas sobre a web o termo push refere-se a estratégias direcionadas às pessoas, independentemente do fato de elas desejarem ou não a informação (por meio de publicidade na televisão, mala direta, telemarketing, e várias formas de publicidade online) e são contrastadas com estratégias pull, cujo objetivo é fazer com que o público-alvo opte ativamente por isto e se engage de maneira mais efetiva com a mensagem. Nesses campos de investigação, a Internet tem sido encarada principalmente como um ambiente pull, com estudiosos da política digital a caracterizando como ambiente "seletivo" (BIMBER \& DAVIS, 2003) ou "orientado para o futuro" (CHADWICK, 2006, p. 175) - embora muitas formas de publicidade online, política ou não, representem estratégias push e dependam de tecnologias push.

Mídias push possibilitando a comunicação direta entre candidato e eleitor são cada vez mais empregadas para atingir os eleitores, a partir de base de dados digitais (recolhidos, entre outras fontes, de mídias sociais) (HOWARD, 2006; KREISS, 2012). Entretanto, nossa pesquisa fornece evidências de que os sites de redes sociais continuam a ser um ambiente pull quando se trata de comunicação candidato-eleitor, e enfatiza a importância desta distinção, tanto conceitual quanto empiricamente, em análises de mídia digital e comunicação política. As distribuições de lei de potência da atenção analisadas aqui sugerem que a propagação destas plataformas raramente permite o tipo de comunicação direta em larga escala entre políticos e pessoas comuns que alguns estudiosos têm discutido. Assim, suas implicações políticas serão mais frequentemente dependentes de como elas são usadas como plataformas para comunicação indireta sobre política (CHADWICK, 2009; GONZALEZ-BAILON, KALTENBRUNNER \& BANCHS, 2010; WOJCIESZAK \& MUTZ, 2009) e de como elas são integradas a uma gama de mudanças institucionais e em estruturas internas na forma como as organizações políticas se organizam e comunicam (BIMBER, 2003; CHADWICK, 2007; HINDMAN, 2008; KARPF, 2012).

Situamos o nosso estudo na discussão mais ampla de mídia digital e comunicação política. Apresentamos nossos métodos e dados, demonstramos quão limitado é o suporte online da maioria dos candidatos - mesmo em eleições de grande importância e com bons recursos - e quão desigualmente o suporte online é distribuído, mesmo em uma amostra de distritos eleitorais competitivos e semelhantes. 


\section{MÍDIA DIGITAL E COMUNICAÇÃO POLÍTICA}

Para campanhas políticas contemporâneas, ferramentas da Internet são partes integrantes de estratégias mais amplas de comunicação. Como foi explicado pelo diretor da campanha de Barack Obama em 2008, David Plouffe (2009, pp. 378-379):

\footnotetext{
Nós tentamos estar nas redes de nossos eleitores-alvo, na TV aberta, a cabo, por satélite e sob demanda; em seus rádios, por toda a Internet, em suas caixas de correio, em seus telefones fixos e em seus celulares; se pudéssemos, estaríamos na porta de suas casas e em suas comunidades. Comunicações balanceadas por todas as mídias são fundamentais em qualquer esforço de mensagens hoje em dia.
}

Mídias tradicionais, como televisão e jornais impressos, e formas antigas de comunicações de campanha, como mala direta, corpo-a-corpo e ligações telefônicas, continuam a ser centrais para os processos de comunicação política, mas, sites de campanha e, cada vez mais, uma ampla presença na web em uma gama de plataformas incluindo sites de mídia social como o Facebook, Twitter e YouTube - são hoje parte integrante da forma como as campanhas tentam se comunicar (BENNETT \& IYENGAR, 2008). Na época das eleições parlamentares intermediárias de 2010, um engajamento online ativo ia além de simplesmente ter um website como parte da definição do que é uma campanha profissional, e a vasta maioria das campanhas usou várias plataformas de mídia social como parte de seu arsenal geral (GULATI \& WILLIAMS, 2011).

Parte do motivo para a rápida difusão de ferramentas de Internet entre campanhas competitivas é que a eficácia da comunicação de campanha tradicional, tais como propagandas de televisão e mala direta, começa a ser questionada, no tocante a como as audiências são fragmentadas e como os impactos diretos sobre o comportamento político, às vezes, são difíceis de serem mensurados (BENNETTT \& IYENGAR, 2008; GREEN \& GERBER, 2008), sugerindo que a Internet e várias mídias sociais - crescentemente parte integral da vida cotidiana para a maioria da população - podem ser complementos necessários para outras formas de comunicação política. O Pew Internet and American Life Project reportou que 75\% dos adultos norte-americanos eram usuários da Internet em 2010, e cerca de 45\% usavam um ou mais sites de redes sociais (SMITH, 2011b, p. 3). Estes níveis elevados e crescentes de uso sugerem um potencial considerável para a comunicação política via ferramentas de Internet. 
Pesquisadores têm abordado a questão do significado da ascensão das mídias digitais para os processos de comunicação política de diferentes maneiras. Como observamos no início deste artigo, uma série de trabalhos procurou compreender o que significam as tecnologias digitais para a comunicação indireta sobre política (em termos de conversas dos cidadãos em sites de mídia social), bem como para as infraestruturas institucionais para a comunicação política (por exemplo, em termos de como campanhas buscam contatos de eleitores). Quando se trata de compreender as implicações das formas específicas de comunicação digital em websites, redes sociais e plataformas de compartilhamento de vídeo, alguns estudiosos têm se centrado sobre a forma como os políticos usam essas ferramentas e argumentam que elas facilitam a comunicação direta em larga escala com os cidadãos; outros estudiosos têm se centrado sobre o comportamento político real das pessoas online e advertido contra o pressuposto de que as campanhas alcançariam grandes audiências na web. Podemos pensar neles como, respectivamente, uma abordagem do lado da oferta e uma abordagem do lado da demanda.

Do lado da oferta, os estudiosos focados no comportamento dos políticos alegaram que a web em suas várias formas permite que os políticos se comuniquem diretamente com os cidadãos. Por exemplo, Zizi Papacharissi (2009) vê o aumento de comunicações de Internet como dando "[capacidade às] elites para se comunicarem diretamente com o eleitorado" (p. 235). Os estudos empíricos nestas linhas se concentraram tanto nas estratégias de campanha quanto na comunicação com as bases eleitorais. Vassia Gueorguieva (2008) destacou a crescente porcentagem de americanos que afirmam que a Internet é a sua principal fonte de notícias durante a campanha eleitoral e argumentou que as mídias sociais proporcionariam aos candidatos exposição a baixo custo e permitiriam que candidatos menos conhecidos pudessem alcançar os eleitores diretamente, sem ter que depender de intermediários, tais como a imprensa. A suposição é repetida em trabalhos posteriores, inclusive o de Shanto Iyengar (2011), que usa a campanha de 2008 de Obama para ilustrar como a "tecnologia da informação fornece aos candidatos os meios de contornar as mídias tradicionais e atingir diretamente os eleitores" (p. 4). Essa suposição também está subjacente a vários estudos sobre o papel do Twitter nas comunicações com o eleitorado (GOLBECK ET AL, 2010; LASSEN \& BROWN, 2011).

A noção de comunicação direta entre políticos e pessoas comuns por meio destas ferramentas não se limita aos Estados Unidos. Pesquisadores têm sugerido a possibilidade de comunicação direta online, generalizada e em larga escala, entre os candidatos e os 
cidadãos em estudos sobre países tão diferentes como, por exemplo, a Dinamarca (SKOVSGAARD \& VAN DALEN, 2013), a Holanda (KUIKEMEIER, VAN NOORT, VLIEGENTHART \& DE VREESE, 2013), a África do Sul (STEENKAMP \& HYDECLARK, 2013), a Coréia do Sul (PARK, LIM, SAMS, NAM \& PARK, 2011) e o Reino Unido (NEWMAN, 2010). Embora muitos reconheçam que tendências para a auto-seleção e o interesse (geralmente baixo) dos usuários nos assuntos públicos dificulte a comunicação política na Internet, estes estudos tendem a se focar sobre o comportamento online dos políticos, analisando o conteúdo de seus sites, perfis em redes sociais etc. A ênfase é sobre as "novas e amplas possibilidades" oferecidas pelas tecnologias digitais que reduziriam os custos iniciais de comunicação com os cidadãos. A suposição adotada é que os políticos (auto-interessados) irão aproveitar essas oportunidades para se envolver com a base eleitoral e com os eleitores potenciais, da mesma forma como eles obtiveram outros eleitores no passado (Mayhew, 1974). Devido ao fato de se concentrarem no lado da oferta da comunicação política digital, i.e., na forma como as elites políticas usam as tecnologias da Internet, estes estudos tendem a prestar pouca atenção às diferentes potencialidades que os aspectos push e pull das ferramentas online fornecem e se as pessoas realmente se envolvem com políticos nas plataformas que estes usam.

Nos estudos sobre campanhas eleitorais empreendidos sob a ótica da demanda, o foco tem sido o comportamento político online das pessoas (em vez de políticos), e esta linha de pesquisa sugere que não devemos esperar que a comunicação direta em larga escala entre as pessoas e os políticos seja a norma online. Os estudos empíricos tem demonstrado que os meios digitais permitem, em sua maioria, que os políticos "preguem para os convertidos" (Norris, 2003), atingindo minorias de apoiadores altamente interessados, enquanto a grande maioria não presta atenção (BIMBER \& DAVIS, 2003; MARGOLIS \& RESNICK, 2000). Isto porque, como um ambiente principalmente pull, a Internet dá aos usuários mais poder de controlar os conteúdos que são trocados no processo de comunicação do que ocorre nos mass media. Como resultado, para que a comunicação direta entre políticos e cidadãos ocorra, via sites de mídias sociais, os usuários devem optar por se envolver em tal interação. Os meios digitais permitem aos eleitores interessados se conectarem diretamente com as elites, mas também proporcionam uma miríade de oportunidades para que aqueles que não estão interessados evitem a política completamente (PRIOR, 2007). Como demonstrado por Matthew Hindman (2008), menos de $0,10 \%$ do tráfego global da web é direcionado para sites políticos, e apenas 3\% envolve 
sites de notícias e de mídia. Este retrato é consistente com as teorias da comunicação política que afirmam que é irracional e impraticável para a maioria dos eleitores monitorar constantemente o cenário político (LUPIA \& MCCUBBINS, 1998; ZALLER, 2003). Isto pode ser especialmente apropriado para cidadãos norte-americanos, já que muitos pesquisadores descobriram interesse modesto e desigual na política eleitoral nos Estados Unidos (ELIASOPH, 1998; HIBBING \& THEISS-MORSE, 2002). Estes estudos têm se concentrado no lado da demanda da política digital, questão paralela à nossa (se os cidadãos realmente se envolvem com políticos online). Eles são, portanto, cruciais para a compreensão da extensão e das condições em que a comunicação política direta por meio das mídias pull ocorre.

Em nossa análise, levamos em conta tanto a difusão das tecnologias digitais entre os candidatos (lado da oferta) quanto o real engajameno online dos cidadãos com candidatos específicos (lado da demanda). Empiricamente, saber se a comunicação direta ocorre por meio de sites de campanha e mídias sociais, depende da topologia do que chamamos de presença na web dos políticos - não as propriedades de seus sites, perfil individual em mídias sociais, ou canal de YouTube, mas suas reais conexões online com o eleitorado nestas plataformas. Examinar a presença na web dos políticos envolve não apenas estudar a adoção e o uso de várias ferramentas de Internet pelas campanhas, nem simplesmente aplicar surveys à população para quantificar os níveis gerais de uso, mas olhar mais de perto para as plataformas onde as pessoas e os políticos realmente se encontram online (FOOT \& SCHNEIDER, 2006; NIELSEN, 2011). Este é o nível em que os nossos dados sobre as eleições intermediárias de 2010 nos leva a sugerir que, embora praticamente todos os candidatos envolvidos em disputas competitivas do Congresso, em 2010, tenham usado uma grande variedade de ferramentas pull de Internet para se comunicar com o eleitorado, a maioria dos candidatos teve sucesso limitado em levar as pessoas a optar ativamente em visitar seus websites, apoiá-los no Facebook, seguir suas contas no Twitter ou ver vídeos em seus canais do YouTube. Quase todos os políticos e a maioria da população estão online, mas a maioria dos indivíduos e os políticos não se encontram online. Indicadores agregados que relatam a porcentagem da população que segue política online obscurecem quão desigualmente é distribuída a atenção aos políticos na web. O grande número de seguidores reunidos por Barack Obama e Sarah Palin - ou ao nível do Congresso por candidatos como Michele Bachmann (Republicana - Minnesota) e Alan Grayson (Democrata - Flórida) - não é representativo da capacidade do político médio em se comunicar com o eleitorado. A maioria das atividades online dos políticos e suas 
implicações políticas são, portanto, melhor compreendidas enfocando a comunicação indireta e mudanças institucionais do que com base em noções de comunicação direta.

\section{MÉTODOS E DADOS}

Para mapear a presença na web dos candidatos nas eleições intermediárias de 2010 dos Estados Unidos e testar se as "novas possibilidades" de comunicação direta entre candidatos e eleitores são, de fato, amplamente realizadas na prática, foram coletados dados em 112 disputas eleitorais competitivas e passíveis de comparação. Os Estados Unidos são, particularmente, um importante estudo de caso, porque a combinação de altos níveis de uso de Internet e de um ambiente de campanha competitivo, profissional e bem financiado sugere que os candidatos vão usar estratégias sofisticadas de comunicação online. Foram selecionadas amostras de distritos com bastante antecedência da eleição sem saber nada sobre o caráter dos candidatos e campanhas, para evitar a tendência de verificar o papel e as implicações das novas tecnologias com base na análise post hoc de algumas campanhas particularmente bem-sucedidas e espetacularmente inovadoras (como a campanha de Dean, em 2004, e a de Obama, em 2008). Para controlar o tamanho do distrito, nós incluimos apenas as disputas para a Câmara dos Deputados. Para examinar sistematicamente o papel das mídias sociais, queríamos um grande número de disputas comparáveis, de alto-risco e com bons recursos, em que seria de esperar que os candidatos e as campanhas tivessem tanto os incentivos quanto os meios para fazer pleno uso de todas as ferramentas à sua disposição. Usando as classificações prospectivas dos distritos de meados de agosto do The New York Times, Congressional Quarterly, do Cook Political Report, e do Real Clear Politics, construímos uma amostra que incluía disputas eleitorais que tivessem sido classificadas por qualquer fonte como "disputada", seja liderada por Republicano ou Democrata, e excluídos todos os distritos que foram classificados por todas as quatro fontes como "seguro" ou "sólido" para qualquer partido. Isso resultou em um total de 112 disputas parlamentares em nossa base de dados ${ }^{4}$. Sendo assim, nos concentramos apenas nos candidatos Democratas e

\footnotetext{
4 Os distritos eleitorais incluídos são: Alabama 2 e 5; Arkansas 1, 2, 3 e 4; Arizona 1, 5 e 8; California 3, 11, 18, 44, 45 e 47; Colorado 3, 4 e 7; Connecticut 4 e 5; Delaware em geral; Florida 2, 8, 12, 16, 22, 24 e 25; Georgia 8 e 12; Hawaii 1; Iowa 1 e 3; Idaho 1; Illinois 8, 10, 11 e 14; Indiana 2, 8 e 9; Kansas 3 e 4; Kentucky 3 e 6; Louisiana 2 e 3; Maryland 1; Massachusetts 10; Michigan 1, 7 e 9; Minnesota 1 e 6; Mississippi 1; Missouri 4; Nebraska 2; Nevada 3; New Hampshire 1 e 2; New Jersey 3, 7 e 12; New Mexico 1 e 2; New York 1, 13, 19, 20, 23, 24, 25 e 29; North Carolina 2, 8 e 11; North Dakota em geral; Ohio 1, 6, 13, 15, 16 e 18; Oregon 5; Pennsylvania 3, 4, 6, 7, 8, 10, 11, 12, 15 e 17; South Carolina 5; South Dakota em geral; Tennessee 4, 6 e 8; Texas 17 e 23; Virginia 2, 5, 9 e 11; Washington 3 e 8; West Virginia 1 e 3; Wisconsin 3, 7 e 8.
} 
Republicanos, excluindo, portanto, os candidatos de partidos menores, cuja falta de recursos e visibilidade afeta fortemente a sua presença online, como outras pesquisas já mostraram (por ex. GULATI \& WILLIAMS, 2007).

Em cada distrito, mapeamos a presença na web dos candidatos e seus seguidores em quatro plataformas: sites pessoais, perfis no Facebook e Twitter, e canais no YouTube. Incluímos websites para avaliar as diferenças e semelhanças entre Web 1.0 e as ferramentas da Web 2.0. Não incluímos a plataforma MySpace, em declínio, nem plataformas menores ou menos populares, como MeetUp, LinkedIn e Vimeo. Foram coletados dados longitudinais sobre a presença e popularidade dos candidatos nessas quatro plataformas online em três estágios, durante o período regular de campanha, entre o Dia do Trabalho e o Dia da Eleição*: no início da campanha (06-08 de setembro), no meio dela (2-4 de outubro), e na fase final (01-02 de novembro, data em que a eleição foi realizada). Nosso quadro de codificação foi estruturado da seguinte forma:

- Para sites de campanha, obteve-se a URL do site em uma pesquisa no Google e uma estimativa dos seus visitantes únicos mensais a partir do serviço de site analytics, disponível publicamente, prestado pela empresa de pesquisa de mercado Compete (www.compete.com).

- Para perfis do Facebook, obteve-se a URL a partir de links diretos nos websites dos candidatos ou, na ausência destes, a partir de uma pesquisa direta do nome do candidato no Facebook. Em seguida, codificamos o número de "likes" (ou "amigos", nas raras ocasiões em que um candidato tinha um perfil pessoal ao invés de uma página pública) para esse perfil. No caso de candidatos que mantiveram vários perfis oficiais, codificamos o perfil vinculado ao site de campanha.

- Para perfis do Twitter, que identificamos por meio do mesmo procedimento do Facebook, codificamos o número de "seguidores" para cada perfil de candidato.

- Para os canais do YouTube, que identificamos por meio do mesmo procedimento relatado para Facebook e Twitter, foram codificados o número de "visualizações totais de upload", que é a soma de todas visualizações de todos os vídeos enviados para um determinado canal.

\footnotetext{
${ }^{*}$ N. do T.: o dia do trabalho nos Estados Unidos é celebrado na primeira segunda-feira de setembro; o dia das eleições ocorre na terça-feira após a primeira segunda-feira de novembro.
} 
Os dados dos quais dependemos aqui têm diferentes graus de validade. Diferentes medidas de tráfego em websites apresentam vantagens e desvantagens, e a maioria enfrenta considerável incerteza ao lidar com os baixos níveis de visitantes únicos ${ }^{5}$. Visualizações de vídeos no YouTube podem estar um pouco superdimensionadas, porque o sistema não detecta várias exibições do mesmo vídeo para usuários que não estão registrados no site ou que não estejam logados durante a sessão (isto pode ter superestimado ligeiramente o número de vezes que os cidadãos assistiram vídeos nestes canais do YouTube, mas o viés introduzido trabalha contra nosso argumento principal). Os dados coletados em sites de mídias sociais são geralmente comportamentais e, portanto, devem ser considerados mais confiáveis. No entanto, tem havido casos (o mais notório dos quais é o do ex- presidente da Câmara dos Deputados, Newt Gingrich), em que candidatos supostamente pagam "agências de seguidores" para a geração de milhares de contas de usuários falsas, a fim de criar a aparência de apoio online para uma campanha específica, de modo que esses dados também devem ser tratados com alguma cautela.

A codificação foi realizada pelos autores, um dos quais codificou todos os candidatos republicanos, o outro, todos os democratas. Para avaliar confiabilidade, foram coletadas amostras aleatórias de 10\% dos distritos em cada fase longitudinal, e cada autor codificou os sites que o outro tinha codificado. Em relação à popularidade dos candidatos em redes sociais, os autores estavam em desacordo em identificar qual era o perfil relevante em apenas dois de 62 candidatos para o Facebook, dois para o YouTube, e um para o Twitter. Quando as diferenças surgiram, foram discutidas e resolvidas por consenso, resultando em procedimentos operacionais padrão que foram empregados na codificação subsequente e contribuíram para o aumento da confiabilidade na codificação de novembro, em comparação com os dois períodos de codificação anteriores.

\footnotetext{
${ }^{5}$ Semelhante a todos os dados provenientes de fontes comerciais, as limitações de nossas medidas de tráfego em websites devem ser reconhecidas. Em primeiro lugar, o indice Compete combina uma amostra nacional selecionada aleatoriamente com dados de provedores de serviços de Internet. Devido a muitas vezes virem de provedores de cabo locais, esses dados tendem a se concentrar em algumas áreas geográficas, o que pode sobrerepresentar algumas regiões. Em segundo lugar, visitantes únicos mensais é uma métrica de audiência menos precisa do que outras, como pageviews, visitas ou o tempo gasto no site. No entanto, tais medidas não estavam disponíveis por meio de qualquer outra fonte acessível ao público. Em nosso ponto de vista, no entanto, fontes de dados alternativas são propensas a apoiar os nossos resultados. Como mostraremos, os padrões de distribuição de tráfego dos websites se assemelham aos de outras medidas de popularidade online e se correlacionam fortemente com elas (ver Tabela 3), assim, passam no teste de validade do critério.
} 


\section{A TOPOLOGIA DE PRESENÇA NA WEB DOS CANDIDATOS NAS ELEIÇÕES INTERMEDIÁRIAS DE 2010}

Os dados destacam quatro características centrais da topologia de presença na web dos candidatos à Camara dos Deputados, nas eleições intermediárias de 2010, que são essenciais para a compreensão da comunicação política online. Todas as quatro características sugerem que estes ambientes de campanha digital pull, onde a comunicação ocorre somente se ambos - candidatos e cidadãos - optarem por isto, raramente levam à comunicação direta generalizada, enfatizando assim a necessidade de uma compreensão mais diferenciada das implicações políticas da mídia digital. A primeira característica é o alcance limitado que a maioria dos candidatos online tem em termos de números absolutos de pessoas que apoiam, seguem, assistem ou os visitam em vários websites. A segunda característica é a distribuição altamente concentrada e desigual de atenção aos esforços online dos candidatos ao longo dos 112 distritos analisados, onde um punhado de candidatos atraiu dezenas de milhares de pessoas, enquanto a maioria se manteve relativamente obscura. A terceira característica é a forte correlação entre a atenção em diferentes plataformas, onde os candidatos que tenham uma presença bem visível em qualquer site são propensos a ser destaque também em outros. A quarta característica da presença na web dos candidatos é que, embora a audiência dos candidatos, em geral, tenha aumentado ao longo dos dois meses - do início de setembro até o dia da eleição em 2 de novembro - os padrões gerais de alcance limitado, a atenção concentrada, e a correlação entre plataformas permanecem os mesmos durante toda a campanha. Vamos discutir cada uma dessas quatro características, por sua vez. Em nossa análise, nós usamos as quatro seguintes medidas de quão visível (em termos de apoiadores, seguidores etc.) é um candidato em uma determinada plataforma, em um determinado mês: número de apoiadores no Facebook e seguidores no Twitter, no momento de uma dada observação, visualizações de vídeo no YouTube sobre o mês da última observação, e de visitantes únicos para um website de campanha.

As figuras 1 a 4 mostram a distribuição da atenção em cada plataforma em novembro, ordenada pela quantidade de atenção que cada candidato atraiu e separado por filiação partidária (incluindo apenas os candidatos realmente usando uma determinada ferramenta). Cada figura é acompanhada por uma caixa listando as medianas de apoiadores/seguidores/visualizações/visitas no mesmo mês. Estes valores demonstram claramente o alcance limitado de presença na web da maioria dos candidatos ao Congresso em 2010. Deixando de lado as diferenças partidárias (que podem, em grande medida, 
depender de um ambiente eleitoral que era hostil aos incumbentes Democratas e não necessariamente se repetirá no futuro), a mediana de atenção dada aos candidatos em cada uma das quatro plataformas examinadas sugere que a maioria tem poucos seguidores online, apesar da ampla disseminação de todas essas ferramentas, tanto entre campanhas quanto cidadãos. Praticamente todos (222 dos 224) candidatos foram amostrados no Facebook, o site de rede social mais popular nos Estados Unidos, em 2010, com uma estimativa de 125 milhões de usuários ativos. 
FIGURA 1. APOIADORES NO FACEBOOK (NOVEMBRO)

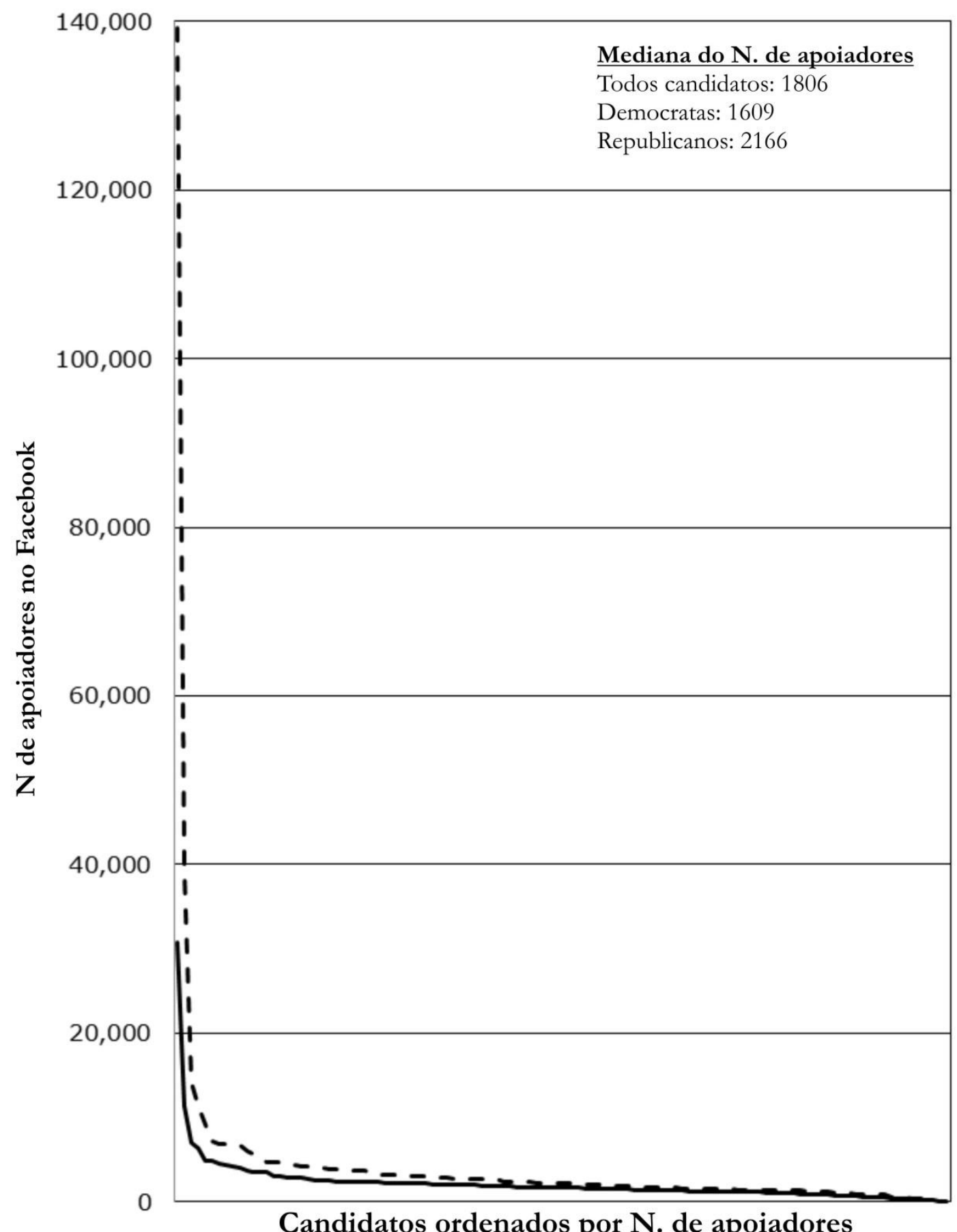

—Democratas - - - Republicanos 
FIGURA 2. SEGUIDORES NO TWITTER (NOVEMBRO)

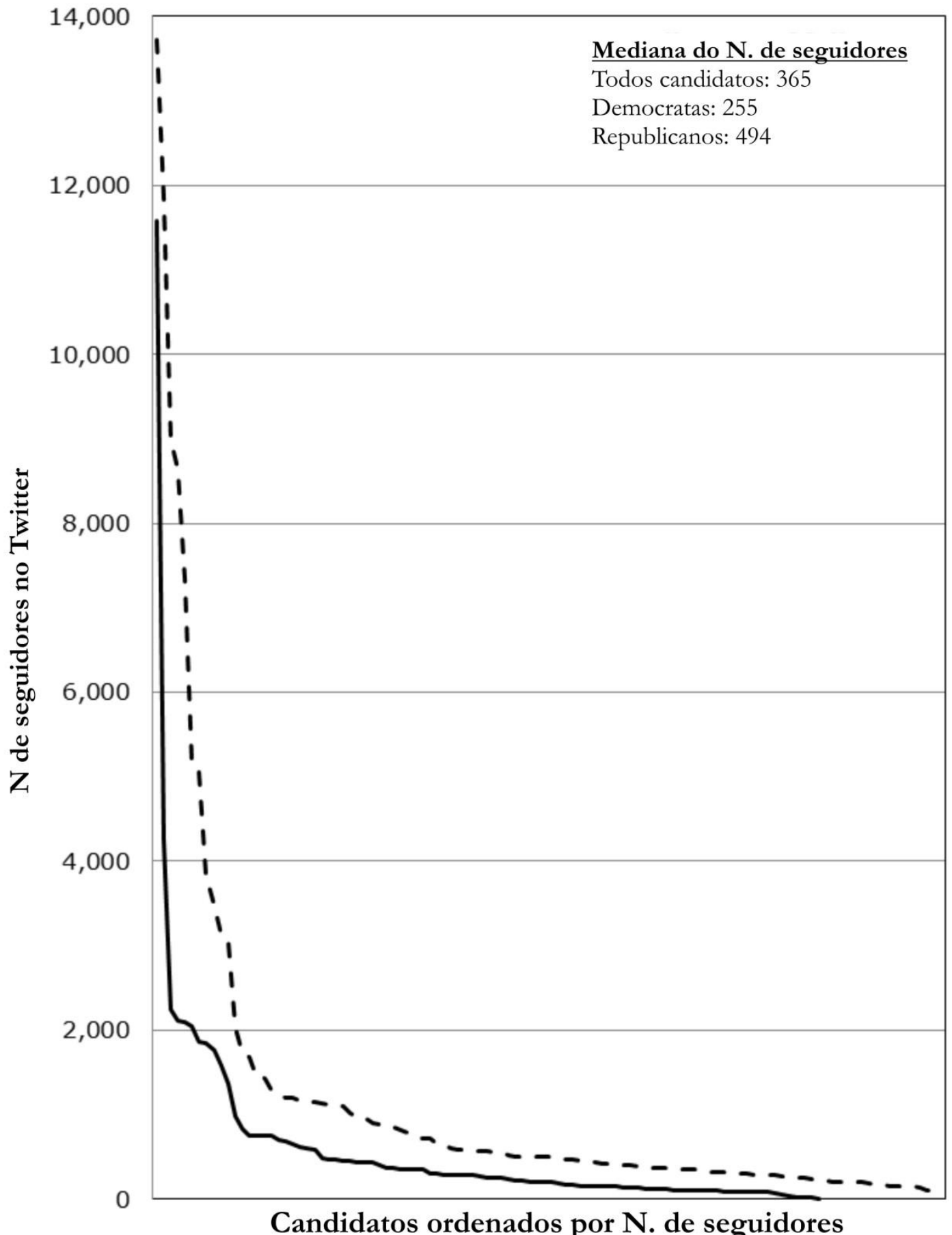

Candidatos ordenados por N. de seguidores

-Democratas - - - Republicanos 
FIGURA 3. VISUALIZAÇÕES NO YOUTUBE (NOVEMBRO)

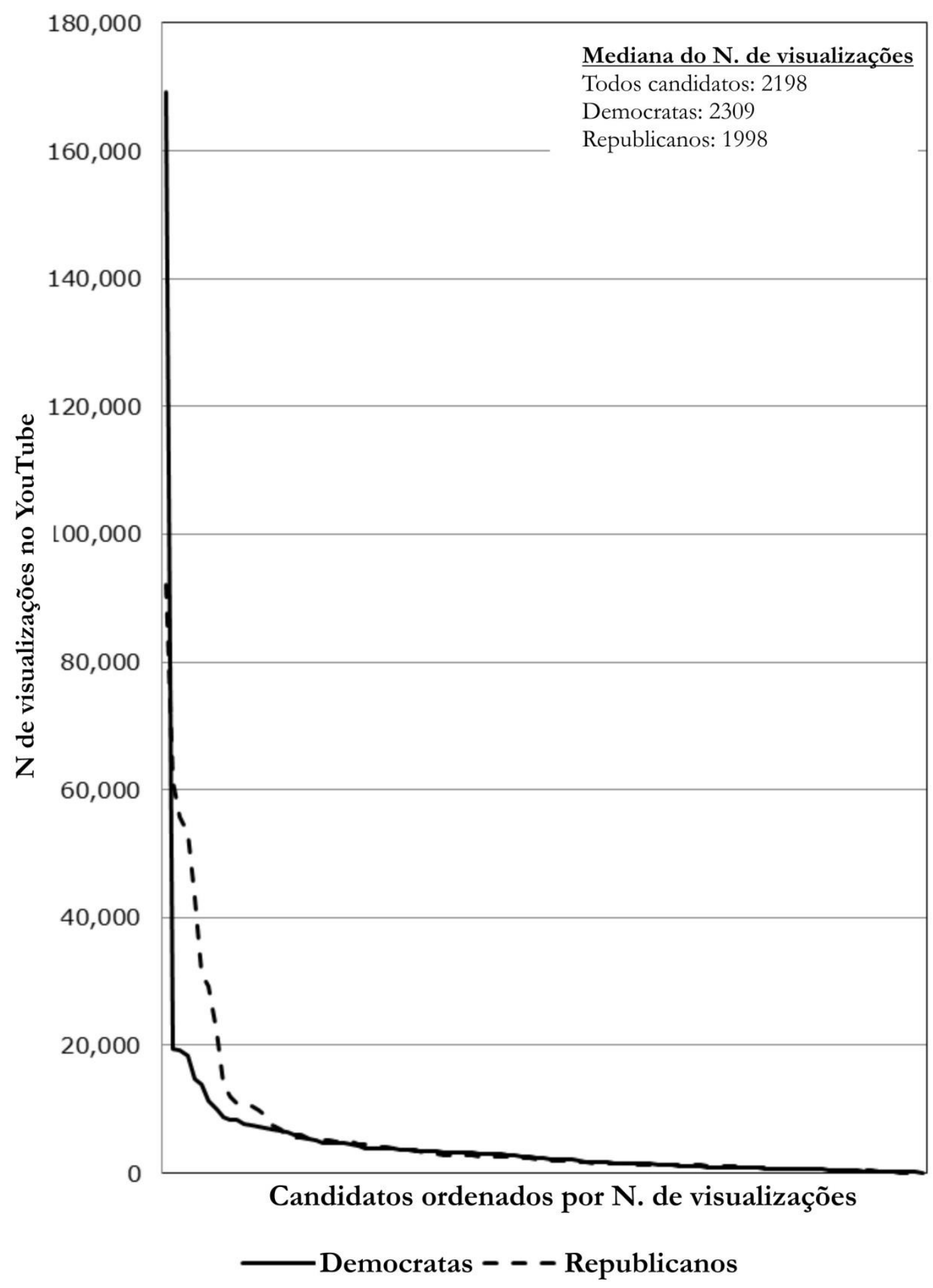


FIGURA 4. TRÁFEGO EM WEBSITE (NOVEMBRO)

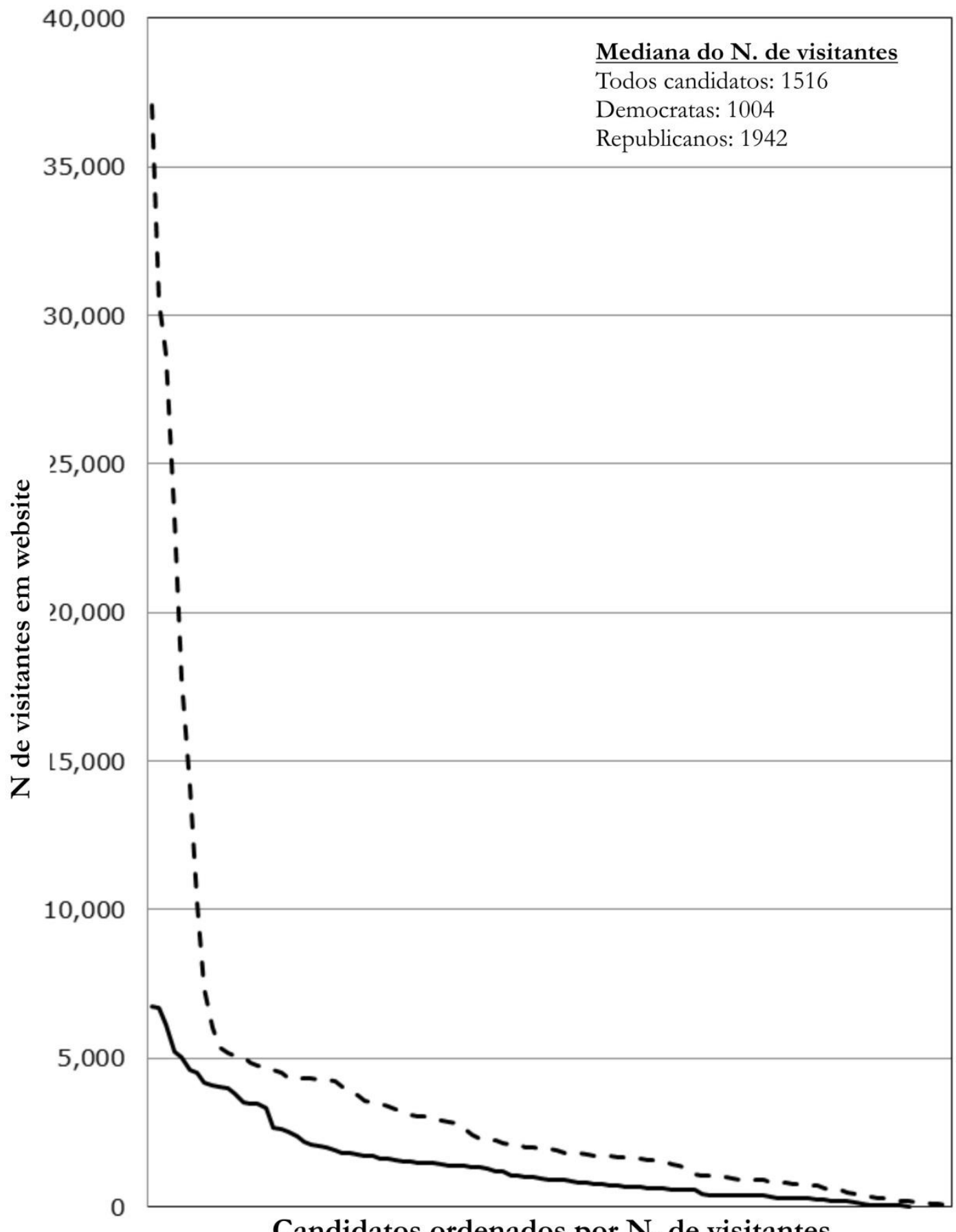

Candidatos ordenados por N. de visitantes

—Democratas - - - Republicanos 
O candidato mediano teve 1.806 apoiadores no dia da eleição, e 95\% dos candidatos tinham menos de 7.000 apoiadores. No Twitter, o terceiro mais popular site de redes sociais nos Estados Unidos, em 2010 (depois de Facebook e MySpace), com dezenas de milhões de contas de usuário, o candidato mediano teve apenas 365 seguidores. 203 candidatos tiveram perfis nesta plataforma, e 95\% tinham menos de 3.500 seguidores. Dos 217 candidatos que tiveram um canal no YouTube, o candidato mediano gerou um total de 2.198 visualizações em todos os seus vídeos postados entre início de outubro e início de novembro; 95\% dos candidatos na amostra gerou menos de 19 mil visualizações ${ }^{6}$. Todos os 224 candidatos tiveram um site da campanha. De acordo com a Compete, o website mediano atraiu 1.516 visitantes únicos em novembro, e 95\% tiveram menos de 6.000 visitantes únicos (ver Tabela 1).

\begin{tabular}{|c|c|c|c|}
\hline Plataforma & Taxa de adoção & Audiência mediana & $\begin{array}{l}95 \% \text { dos candidatos } \\
\text { tiveram menos de... }\end{array}$ \\
\hline Facebook & $99 \%$ & 1,806 & 7,000 apoiadores \\
\hline Twitter & $91 \%$ & 365 & 3,500 seguidores \\
\hline YouTube & $97 \%$ & 2,198 & 19,000 visualizações \\
\hline Website & $100 \%$ & 1,516 & 6,000 visitantes únicos \\
\hline
\end{tabular}

Para colocar estes números em perspectiva, considere que os candidatos concorrem em distritos com uma população média de cerca de 700 mil habitantes. Em uma eleição intermediária com baixo comparecimento esperado, seu objetivo de votação será 100 mil ou mais e seu público-alvo para anúncios de televisão, mala direta, e agenda de campo será de 250 mil ou mais, dependendo dos recursos disponíveis. Em termos de comunicação direta com o eleitorado, 1.806 apoiadores do Facebook ou 2.198 visualizações de vídeos do YouTube não é muito. Dado o número muito elevado de usuários nestas plataformas, a baixa penetração é uma explicação improvável para a relativa ausência de interesse em candidatos online. Embora $75 \%$ da população adulta seja utilizadora da

\footnotetext{
6 O fato de que os números do YouTube são superiores aos de Facebook e Twitter não significa necessariamente que os candidatos atraiam mais a atenção no YouTube, em comparação com outros canais de campanha online. Enquanto só se pode curtir ou seguir um candidato uma vez no Facebook e no Twitter (e pode parar de fazer isso), e enquanto ninguém precisa visitar um site de candidato apenas uma vez por mês para ser contado como um usuário único mensal, o número total de visualizações em um canal do You'Tube é cumulativo ao longo do tempo e aditivo em todos os vídeos enviados. Já que a maioria das campanhas tem dezenas de vídeos em seus canais do YouTube, o total de visualizações de vídeos em seus canais é, provavelmente, consideravelmente maior do que o número de espectadores únicos de seus vídeos. Uma medida deste último, infelizmente, não está disponível ao público e só é mal representada pelo número de assinantes do canal, visto que poucas pessoas se inscrevem em canais do YoúTube dos candidatos: em novembro, a média do número de assinantes dos canais de nossos candidatos foi de 61 e a mediana foi de 14 .
} 
Internet e 45\% seja ativa em um ou mais sites de redes sociais (Smith, 2011a), fotos de bebês frequentemente atraem mais atenção online do que políticos buscando a eleição para a Câmara dos Deputados.

Como no caso da campanha presidencial, onde Obama e Palin geraram muito interesse online e atraíram muitos adeptos, um punhado de candidatos ao Congresso se fez destacar da multidão. No Facebook, os mais notáveis são Michele Bachmann (Republicana), reeleita em seu distrito de Minnesota, e Alan Grayson (Democrata), que perdeu em seu distrito, na Flórida. Ambos são proeminentes em toda a web (bem como em canais de notícias a cabo). Bachmann teve 139.203 apoiadores no Facebook no dia da eleição, e Grayson teve 30.807. Dos 222 candidatos no Facebook, apenas seis tiveram mais de 10.000 apoiadores.

Isso não ocorre apenas para esta plataforma ${ }^{7}$. A atenção é altamente concentrada em todos os âmbitos. Por causa das desigualdades observadas, as médias nos dizem pouco sobre a visibilidade online dos candidatos, e nós usamos medianas em seu lugar, para nos aproximarmos do resultado modal - isto sugere que Steve Kagen (Democrata-WI), com seus 1.633 apoiadores do Facebook em novembro, 88 seguidores no Twitter, 1.009 visualizações de vídeos You'Tube no mês, até o dia da eleição, e 1.417 visitantes únicos ao seu site de campanha, em novembro, é mais representativo da atenção à presença na web da maioria dos candidatos do que proeminentes outliers, como Bachmann e Grayson. Kagen está presente em toda parte online, mas poucas pessoas parecem se importar. Embora seja crucial entender quais os fatores que explicam a alta popularidade online dos poucos e excepcionais outliers, é igualmente importante reconhecer que a maioria dos candidatos atrai audiências muito pequenas nestas plataformas, a despeito de seus esforços para estarem visíveis em tantos sites quanto possível.

A segunda característica importante da topologia da presença na web dos candidatos em 2010 é que a atenção dos eleitores esteve altamente concentrada em todas as plataformas. Uma maneira de quantificar a concentração de apoio online em todos os 224 candidatos examinados é por meio do cálculo do coeficiente de Gini para cada plataforma (uma métrica que, por exemplo, Hindman (2008) utilizou para analisar a concentração de tráfego de Internet). O coeficiente de Gini para uma dada população e recursos assume

\footnotetext{
${ }^{7}$ No Twitter, Jesse Kelly (Republicano-AZ) e Sean Duffy (Republicano-WI) tiveram ambos mais de 10 mil seguidores, e, além de alguns candidatos já mencionados, Raul Labrador (Republicano-ID), Rene Ellmers (Republicano-NC) e Jon Runyan (Republicano-NJ) tiveram mais de 10 mil visitantes únicos para seus sites em novembro. Grayson é o único Democrata, de 112, que atraiu mais de 10 mil apoiadores, seguidores ou visitantes únicos no Facebook, Twitter ou sites de campanha.
} 
valores entre 0 e 1 , com valores mais altos correspondendo a uma maior desigualdade. A Tabela 2 apresenta os coeficientes de Gini para Facebook, Twitter, YouTube, e tráfego em websites de setembro até novembro.

\section{TABELA 2 - COEFICIENTE DE GINI PARA A ATENÇÃO EM TODAS AS PLATAFORMAS E OBSERVAÇÕES}

\begin{tabular}{|c|c|c|c|c|c|c|c|}
\hline \multirow{2}{*}{\multicolumn{3}{|c|}{$\frac{\text { Setembro }}{\text { Democratas }}$}} & \multicolumn{2}{|c|}{ Outubro } & \multicolumn{3}{|c|}{ Novembro } \\
\hline & & & Repul & nocratas & Republicanos & Democratas & $\begin{array}{l}\text { Republican } \\
\text { os }\end{array}$ \\
\hline Facebook & .44 & .59 & & .46 & .56 & .44 & .60 \\
\hline Twitter & .72 & .66 & & .67 & .65 & .66 & .64 \\
\hline YouTube & & & .68 & & .73 & .73 & .74 \\
\hline Website & .57 & .54 & & .51 & .50 & .51 & .59 \\
\hline
\end{tabular}

Nota: Para o YouTube, os valores de outubro são calculados como o acúmulo das visualizações de vídeos entre setembro e outubro, e os valores de novembro são o acumulado entre outubro e novembro.

A concentração varia ao longo das quatro plataformas, com o Facebook variando de um mínimo de .44 e um máximo de .60 , Twitter de .64 a .72, YouTube de .68 a .74 e tráfego em websites de .50 a .59 . Facebook e websites são os menos desiguais e variam o mínimo ao longo dos dois meses. Mas, a atenção em todas as quatro plataformas em todas as três observações é mais concentrada do que a renda nos Estados Unidos (estimada em .38 pela OCDE (2011)). Esta forte concentração também se reflete nas Figuras 1 a 4, que mostraram uma típica distribuição de lei de potência da atenção em todas as quatro plataformas. ${ }^{8}$

A terceira característica importante da topologia de presença na web dos candidatos em 2010 é que a atenção em qualquer plataforma é altamente correlacionada com a atenção em outras plataformas. A Internet é um espaço irregular em que o sucesso em uma plataforma, muitas vezes anda de mãos dadas com o sucesso em outras plataformas. A Tabela 3 apresenta os coeficientes de correlação de Pearson entre os valores registrados para o suporte em cada uma das quatro plataformas em novembro. Cada

\footnotetext{
${ }^{8}$ Usamos vários métodos para testar se esta foi realmente uma distribuição de lei de potência. Primeiro, os testes de Shapiro-Wilk de normalidade retornaram valores que justificam a rejeição da hipótese nula de que os dados são normalmente distribuídos (as estatísticas foram .187 para o Facebook, .460 para o Twitter, .420 para o YouTube e .440 para os websites; para todos deles $p=.000$ ). Posteriormente, rodamos modelos de regressão de mínimos quadrados ordinários com os valores registrados como variáveis. Tomando Facebook como exemplo, a variável dependente foi o registro de "curtidas" que um candidato recebeu e a variável independente foi o registro do número de outros candidatos que receberam pelo menos tantas "curtidas" quanto o candidato em questão. A mesma lógica aplica-se a regressão com base em seguidores no Twitter, visualizações no YouTube, e visitas à sites. Os modelos se ajustaram aos dados muito bem, com coeficientes $\mathrm{R}^{2}$ de .825 para curtidas no Facebook, .794 para seguidores no Twitter, .821 para visualizações no YouTube, .904 para o tráfego em websites. A estrutura empírica dos nossos dados, assim, se assemelha de perto ao padrão que seria esperado se seguisse uma distribuição de lei de potência pura e está em sintonia com o que os outros têm encontrado em outras áreas sobre atividade online.
} 
correlação é altamente significativa $(p=.000)$ e bastante forte (variando de .328 a .503 ). ${ }^{9} \mathrm{~A}$ correlação mais forte encontada foi entre o apoio no Facebook e no Twitter, enquanto as visualizações de vídeos do YouTube e os visitantes nos websites apresentam a correlação mais fraca. Facebook é mais correlacionado com outras plataformas, enquanto os visitantes dos websites estão menos correlacionados com os demais ambientes, sugerindo que as mídias sociais, que proporcionam fácil compartilhamento, direcionam mais tráfego para outras plataformas do que simples links em websites.

\section{TABELA 3 - CORRELAÇÕES ENTRE MEDIDAS DE ATENÇÃO SOBRE DIFERENTES} PLATAFORMAS

\begin{tabular}{|c|c|c|c|c|c|c|c|c|}
\hline \multirow[t]{4}{*}{ Facebook } & & & \multicolumn{2}{|l|}{ Twitter } & \multicolumn{2}{|c|}{ You'Tube } & \multicolumn{2}{|l|}{ Website } \\
\hline & \multicolumn{2}{|c|}{ Coeficiente de } & \multicolumn{2}{|c|}{ Coeficiente de } & \multicolumn{2}{|c|}{ Coeficiente de } & \multicolumn{2}{|c|}{ Coeficiente } \\
\hline & Pearson & & Pearson & & Pearson & & de Pears & \\
\hline & $\mathrm{R}$ & $n$ & $R$ & $n$ & $\mathrm{R}$ & $n$ & $\mathrm{R}$ & $n$ \\
\hline Facebook & - & 201 & $.503^{* * *}$ & 216 & $.406^{* * *}$ & 204 & $.423^{* * *}$ & \\
\hline Twitter & $.503 * * *$ & 201 & - & & $.338^{* * *}$ & 196 & $.332 * * *$ & 191 \\
\hline You'Tube & $.406 * * *$ & 216 & $.338 * * *$ & 196 & - & & $.328 * * *$ & 200 \\
\hline Website & $.423^{* * *}$ & 204 & $.332 * * *$ & 191 & $.328 * * *$ & 200 & - & \\
\hline
\end{tabular}

Nota: Todos valores se referem a novembro e estão em log. *** $p \leq .000$.

A quarta característica importante da topologia da presença na web dos candidatos é a sua estabilidade relativa. Enquanto a visibilidade da maioria dos candidatos aumentou na maioria das plataformas de setembro a novembro, e alguns candidatos expandiram drasticamente a sua presença na web, os padrões globais de alcance limitado, concentração e correlação entre as plataformas permaneceram os mesmos durante todo período de campanha. Deixando de lado aqueles que se envolveram em primárias tardias e aqueles que entraram na plataforma apenas mais tarde, um total de 199 candidatos, em nosso conjunto de dados, estiveram no Facebook de setembro ao início de novembro. Durante estes dois meses, o número combinado de apoiadores no Facebook cresceu 30\%, mais de 150 mil em números absolutos. Mas apenas dois candidatos, os republicanos Michele Bachmann (aumento de quase 67 mil) e Mary Bono Mack (Republicano-CA, com um aumento de mais de 10 mil), são responsáveis por metade do crescimento. A variação média no número de adeptos entre os 199 candidatos no Facebook de setembro a novembro foi de apenas 300. Vários deles, na verdade, perderam apoiadores, uma vez que eles mudaram páginas de perfil e não foram capazes de migrar antigos apoiadores de uma

\footnotetext{
${ }^{9}$ Os valores foram registrados para levar em conta a distribuição de lei de potência dos dados.
} 
página para outra. Notavelmente, dentre aqueles que perderam apoiadores está Dan Benishek (Republicano-MI), que passou de impressionantes 22.209 fãs em setembro para, abaixo da média, 1.382 em novembro ${ }^{10}$. Como mostrado pelos coeficientes de Gini, relativamente estáveis na Tabela 2 , dois meses de crescimento não afetaram em nada a distribuição altamente concentrada e desigual de apoio no Facebook. Da mesma forma, o número total de seguidores dos 180 candidatos que estavam ativos no Twitter do início de setembro ao início de novembro cresceu $17 \%$ - pouco mais de 23 mil. Aqui, o crescimento foi um pouco menos concentrado, com nove candidatos respondendo por metade do crescimento e o coeficiente de Gini, portanto, caindo um pouco ao longo da campanha, tanto entre democratas quanto republicanos.

\section{CONCLUSÕES}

Este artigo procurou analisar se nas eleições parlamentares intermediárias nos Estados Unidos, em 2010, ocorreu uma comunicação direta generalizada entre as pessoas e os políticos via pull media no Facebook, Twitter, YouTube e sites de campanha. Com base na análise dos 112 distritos eleitorais mais competitivos, podemos concluir que isso não aconteceu. Em todas as quatro plataformas da web mais usadas, no que diz respeito à grande maioria dos candidatos, o tipo de comunicação direta entre candidato e eleitor que Golbeck et al. (2010), Gueorguieva (2008), e Iyengar (2011), assim como muitos outros acadêmicos que estudam política digital em países para além dos Estados Unidos, têm recentemente destacado como algo possível graças a sites de redes sociais, continua a ser exatamente isso: uma possibilidade. Entretanto, não é algo que realmente ocorra em larga escala para a maioria dos candidatos, como pudemos observar.

Um exame mais detalhado da presença na web dos 224 candidatos revela um terreno caracterizado por quatro características que desafiam a noção de que os candidatos se comunicam diretamente com um número significativo de cidadãos online: (1) alcance limitado, em termos do número de pessoas que seguem a maioria das campanhas em diversas plataformas; (2) elevados níveis de concentração de atenção em todas as plataformas, com alguns políticos obtendo muitos seguidores e a maioria obtendo poucos;

\footnotetext{
10 A mudança ocasional de perfil por parte dos candidatos, com o novo perfil muitas vezes falhando em chamar apoiadores antigos, tornou problemático medir o suporte online ao longo do tempo. Adicionar os números de apoiadores em todos os perfis de candidatos teria sobrerrepresentado a popularidade devido a prováveis altas taxas de duplicação, e ignorar uma mudança na autodefinição de uma campanha sobre que é sua presença oficial da web teria sido arbitrário. Nós, portanto, optamos por adotar as campanhas em suas próprias palavras e medir as audiências das mídias sociais indicadas em seus websites.
} 
(3) correlações significativas entre a visibilidade em cada plataforma, onde os candidatos que vão bem em uma também tendem a ir bem nas outras; e (4) aumento considerável do número total de pessoas que seguem candidatos no decurso do período de campanha, sem qualquer alteração no padrão geral de distribuição altamente distorcida.

Estes achados desafiam a noção de que ferramentas pull de Internet, como sites de campanha e perfis de mídias sociais, facilitem a comunicação direta em larga escala entre candidatos e cidadãos. Apesar de nossa análise apoiar estudos que mostraram a ampla adoção de novas ferramentas de comunicação de campanha entre os candidatos, pelo lado da oferta (GULATI \& WILLIAMS, 2007; 2011), o tamanho pequeno de seu público apóia a perspectiva de que a maior parte da comunicação política atinge diretamente apenas uma pequena minoria no lado da demanda, provavelmente aqueles que já estavam interessados no político em questão (como, aliás, observado por outros autores para as gerações anteriores de ferramentas de Internet, cf., por exemplo, Bimber \& Davis, 2003; Norris, 2003). Apenas poucos políticos e candidatos excepcionais atraem um substancial número de seguidores online, enquanto a maioria dos candidatos alcançam poucos indivíduos, mesmo quando eles usam ferramentas populares da Internet, como o Facebook. Isto sugere que os poucos candidatos com audiências online significativas não estão tanto à frente da curva, uma vez que estão acima da curva. Se o número limitado de políticos da nossa amostra que atraíram muita atenção são diferenciados por terem sido os primeiros a adotarem plataformas específicas, talvez outros possam fazer o mesmo e alcançar resultados semelhantes. Mas, com as taxas de adoção das quatro plataformas consideradas aqui variando entre $91 \%$ e $100 \%$, entre os candidatos, e grande parte da população adulta já usando tais plataformas regularmente, as distribuições altamente irregulares claramente não são o resultado de níveis desiguais de uso. Identificar os fatores causais por trás dessa variação é, obviamente, importante e é uma tarefa que assumimos em outro estudo (VACCARI \& NIELSEN, 2013). Este artigo procurou analisar de forma sistemática alguns padrões empíricos, muitas vezes negligenciados, que desafiam os pressupostos e generalizações correntes na pesquisa acadêmica e, especialmente, entre os profissionais da política e jornalistas. Há uma oferta online abundante de candidatos, em uma variedade de plataformas, mas, poucas pessoas prestam atenção à maioria deles. Como sugerido no início deste artigo, isto é atribuível, pelo menos em parte, à combinação de um ambiente de alta possibilidade de escolha (PRIOR, 2007) onde a dinâmica pull direciona o uso de mídia (NEUMAN et al., 2012), com o limitado e desigualmente distribuído interesse da maioria 
dos norte-americanos em política (ELIASOPH, 1998; HIBBING \& THEISS-MORSE, 2002). Em tal ambiente, push medias - incluindo tradicional (como a publicidade televisiva e mala direta), digital (como microssegmentação dos eleitores individuais por meio de mensagens personalizadas entregues em vários veículos online, tais como a publicidade em buscadores de internet) e misto (como operações de campo orientadas por dados, incluindo a prospecção de votos porta-a-porta e via telefone) - continuam a ser os mais importantes canais de comunicação direta em larga escala entre candidatos e eleitores. Nosso argumento sugere, também, um potencial considerável para a pesquisa comparativa - se nós assumirmos, por exemplo, que os candidatos em dois países diferentes, ambos caracterizados por um ambiente de mídia de alta escolha, adotem ferramentas de mídia social similares para fins políticos, os resultados poderão ser significativamente diferentes se existirem diferenças nacionais acentuadas na escala e no alcance do interesse em política. Enquanto os padrões e dinâmicas aqui identificados permanecerem, a maioria dos políticos não será capaz de confiar em seus websites e sua presença em mídias sociais para envolverse em comunicação direta com o eleitorado em qualquer escala significativa - não tanto porque os políticos não o desejem, mas, porque a maioria das pessoas não se importa muito com os candidatos, pelo menos no modo como a maioria das campanhas são organizadas atualmente nos Estados Unidos. Alguns candidatos outliers obtêm muitos seguidores, mas a maioria dos políticos não consegue construir extensas audiências. Conforme já enfatizado, a pouca comunicação direta que a maioria dos políticos gerencia envolvendo os indivíduos não significa que a crescente popularidade de tais ferramentas, incluindo plataformas de mídia social, não tem implicações políticas. Gostaríamos de salientar, em particular, duas áreas. A primeira diz respeito ao acesso à internet e, por vezes, à comunicação indireta em larga escala sobre política em vários fóruns online, muitos dos quais permitem novas formas de compartilhamento, remixagem e comentários (CHADWICK, 2009; GONZALEZ-BAILON et al, 2010; WOJCIESZAK \& MUTZ, 2009). Mesmo que a comunicação com os medianos 365 seguidores no Twitter possa não ajudar muito um candidato, o que as pessoas dizem sobre o candidato no Twitter pode importar (especialmente nos casos em que os jornalistas começam a usar material de mídia social como parte de sua cobertura de notícias). A segunda área diz respeito às implicações institucionais de como as tecnologias digitais estão cada vez mais sendo parte integrante de mudanças na forma como as campanhas são organizadas e nos atores que se envolvem com elas e de que forma (BIMBER, 2003; CHADWICK, 2007; HINDMAN, 2008; KARPF, 2012). É improvável que a atração de 1.806 apoiadores no Facebook afete um 
resultado eleitoral, mas mobilizá-los como voluntários ou doadores pode fazer a diferença, especialmente em disputas apertadas e na política partidária interna, como, por exemplo, em eleições primárias. Sites de redes sociais e meios pull similares podem apenas raramente facilitar a comunicação em larga escala entre os candidatos e os cidadãos, mas podem tornar-se parte das infraestruturas institucionais (incluindo bancos de dados de grande escala) que os maiores partidos e campanhas estão construindo para atingir os eleitores por meio de outras formas de comunicação push (BENNETT \& MANHEIM, 2006; HOWARD, 2006; KREISS, 2012). Ambos os tipos de pesquisas, sejam as focadas na comunicação indireta ou em mudanças institucionais, vão além da análise da comunicação política digital em termos de efeitos comportamentais de nível individual, e ambos merecem mais atenção por parte dos pesquisadores.

Enquanto a competição por atenção for tão feroz e os níveis de atenção tão baixos e desiguais, apenas alguns políticos irão atrair uma grande audiência online que permita a eles se comunicarem diretamente com o eleitorado, em graus significativos, por meio de vários sites de redes sociais. O resto terá que encontrar outras maneiras, incluindo tanto os meios tradicionais, como mala direta, operações de campo e publicidade televisiva, assim como novas formas de campanha de marketing online. A topologia que nós mapeamos aqui é dominada por alguns poucos outliers que atraem dezenas de milhares de apoiadores e espectadores, mas onde a grande maioria dos candidatos - mesmo em disputas com amplos recursos financeiros, competitivas e de alto grau de incerteza quanto aos resultados - trabalham em relativa obscuridade virtual. Como pesquisadores de comunicação política apenas começaram a explorar este novo ambiente de campanha online, devemos compreender tanto a atuação dos candidatos raros, proeminentes e de alto impacto potencial na web, como também da ampla maioria de políticos que conseguiram apenas um modesto número de seguidores online. Para cada Michele Bachmann e Alan Grayson seguidos por dezenas de milhares, há 50 ou mais Steve Kagens, ou seja, candidatos com alguns milhares de apoiadores online que precisam encontrar outras maneiras de se comunicarem com o eleitorado, candidatos que provavelmente falam com mais pessoas pessoalmente ao longo da campanha do que com o uso de Facebook e Twitter. 


\section{REFERÊNCIAS BIBLIOGRÁFICAS}

BENNETT, W. L., \& IYENGAR, S. (2008). A new era of minimal effects? The changing foundations of political communication. Journal of Communication, 58(4), 707-731.

doi:10.1111/j.1460-2466.2008.00410.x

BENNETT, W. L., \& MANHEIM, J. B. (2006). The one-step flow of communication. Annals of the American Academy of Political and Social Science, 608(1), 213-232. doi:10.1177/0002716206292266

BIMBER, B. A. (2003). Information and American democracy: Technology in the evolution of political power. Cambridge, UK: Cambridge University Press.

BIMBER, B. A., \& DAVIS, R. (2003). Campaigning online: The Internet in U.S. elections. New York, NY: Oxford University Press.

CHADWICK, A. (2006). Internet politics: States, citizens, and new communication technologies. New York, NY: Oxford University Press.

CHADWICK, A. (2007). Digital network repertoires and organizational hybridity. Political Communication, 24(3), 283-301. doi:10.1080/10584600701471666

CHADWICK, A. (2009). Web 2.0: New challenges for the study of e-democracy in an era of informational exuberance. I/ S: Journal of Law and Policy for the Information Society, 5(1), 941. Retrieved from

http://heinonline.org/HOL/Page?handle=hein.journals/isjlpsoc5\&div=6\&g_sent=1\&coll ection=journals

COLEMAN, S., \& BLUMLER, J. G. (2001). Realising democracy online: A civic commons in cyberspace. London, UK: IPPR.

ELIASOPH, N. (1998). Avoiding politics: How Americans produce apathy in everyday life. Cambridge, UK: Cambridge University Press.

FOOT, K., \& SCHNEIDER, S. (2006). Web campaigning. Cambridge, MA: MIT Press.

GOLBECK, J., GRIMES, J. M., \& ROGERS, A. (2010). Twitter use by the U.S. Congress. Journal of the American Society for Information Science and Technology, 61(8), 1612-1621. doi:10.1002/asi.21344

GONZALEZ-BAILON, S., KALTENBRUNNER, A., \& BANCHS, R. E. (2010). The structure of political discussion networks: A model for the analysis of online deliberation. Journal of Information Technology, 25(2), 230-243. doi:10.1057/jit.2010.2

GREEN, D. P., \& GERBER, A. S. (2008). Get out the vote. Washington, DC: Brookings Institution Press.

GUEORGUIEVA, V. (2008). Voters, MySpace, and YouTube: The impact of alternative communication channels on the 2006 election cycle and beyond. Social Science Computer Review, 26(3), 288-300. doi:10.1177/0894439307305636 
GULATI, G. J., \& WILLIAMS, C. B. (2007). Closing the gap, raising the bar: Candidate web site communication in the 2006 campaigns for congress. Social Science Computer Review, 25(4), 443-465. doi:10.1177/0894439307305624

GULATI, J., \& WILLIAMS, C. B. (2011). Social media in the 2010 congressional elections. SSRN eLibrary. Retrieved from

http://papers.ssrn.com/sol3/papers.cfm?abstract_id=1817053

HIBBING, J. R., \& THEISS-MORSE, E. (2002). Stealth democracy. Cambridge, UK: Cambridge University Press.

HINDMAN, M. S. (2008). The myth of digital democracy. Princeton, NJ: Princeton University Press.

HOLBERT, R. L., GARRETT, R. K., \& GLEASON, L. S. (2010). A new era of minimal effects? A response to Bennett and Iyengar. Journal of Communication, 60(1), 15-34. doi:10.1111/j.1460-2466.2009.01470.x

Howard, P. N. (2006). New media campaigns and the managed citizen. Cambridge, UK: Cambridge University Press.

IYENGAR, S. (2011). The media game: New moves, old strategies. The Forum, 9(1). Retrieved from http://www.degruyter.com/dg/viewarticle.fullcontentlink:pdfeventlink/contentUri?t:ac=j\$ 002ffor.2011.9.1_20120105083457\$002ffor.2011.9.1\$002ffor.2011.9.1.1425\$002ffor.2011.9 .1.1425.xml

KARPF, D. (2012). The MoveOn effect. New York, NY: Oxford University Press.

KREISS, D. (2012). Taking our country back. New York, NY: Oxford University Press. Kruikemeier, S., van Noort, G., Vliegenthart, R., \& de Vreese, C. H. (2013). Getting closer: The effects of personalized and interactive online political communication. European Journal of Communication, 28(1), 53-66. doi:10.1177/0267323112464837

LASSEN, D. S., \& BROWN, A. R. (2011). Twitter: The electoral connection? Social Science Computer Review, 29(4), 419-436. doi:10.1177/0894439310382749

LUPIA, A., \& MCCUBBINS, M. (1998). The democratic dilemma: Can citizens learn what they need to know? Cambridge, UK: Cambridge University Press.

MARGOLIS, M., \& RESNICK, D. (2000). Politics as usual. Thousand Oaks, CA: SAGE Publications.

MAYHEW, D. R. (1974). Congress: The electoral connection. New Haven, CT: Yale University Press.

NEUMAN, W. R., PARK, Y. J., \& PANEK, E. (2012). Tracking the flow of information into the home: An empirical assessment of the digital revolution in the U.S. from 19602005. International Journal of Communication, 6. Retrieved from http://ijoc.org/index.php/ijoc/article/view/1369/745 
NEWMAN, N. (2010). \#UKelection2010, mainstream media and the role of the Internet: How social and digital media affected the business of politics and journalism. Oxford, UK: Reuters Institute for the Study of Journalism.

NIELSEN, R. K. (2011). Mundane Internet tools, mobilizing practices, and the coproduction of citizenship in political campaigns. New Media \& Society, 13(5), 755-771. doi:10.1177/1461444810380863

NORRIS, P. (2003). Preaching to the converted? Pluralism, participation and party websites. Party Politics, 9(1), 21-45. doi:10.1177/135406880391003

OECD. (2011). Divided we stand: Why inequality keeps rising. Paris, France: OECD. Papacharissi, Z. (2009). The virtual sphere 2.0: The Internet, the public sphere, and beyond. In A. Chadwick \& P. N. Howard (Eds.), The Routledge handbook of Internet politics (pp. 230 245). New York, NY: Routledge.

PARK, S. J., LIM, Y. S., SAMS, S., NAM, S. M., \& PARK, H. W. (2011). Networked politics on Cyworld: The text and sentiment of Korean political profiles. Social Science Computer Review, 29(3), 288-299. doi:10.1177/0894439310382509

PLOUFFE, D. (2009). The audacity to win. New York, NY: Viking.

PRIOR, M. (2007). Post-broadcast democracy. New York, NY: Cambridge University Press.

RUSSELL, M. (2011). Mining the social web. Sebastopol, CA: O’Reilly.

SHIRKY, C. (2003). Power laws, weblogs, and inequality. Retrieved from http://shirky.com/writings/powerlaw_weblog.html

SKOVSGAARD, M., \& VAN DALEN, A. (2013). Dodging the gatekeepers? Information, Communication \& Society, 16(5), 737-756. doi:10.1080/1369118X.2013.783876

SMITH, A. (2011a). The Internet and campaign 2010. Washington, DC: Pew Research Center. Retrieved from

http://pewinternet.org/ /media//Files/Reports/2011/Internet $\% 20$ and $\% 20$ Campaign $\% 2$ 02010.pdf

SMITH, A. (2011b). Social media and the 2010 election. Washington, DC: Pew Research Center. Retrieved from http://pewinternet.org/ /media//Files/Reports/2011/PIPSocial-Media-and-2010-Election.pdf

STEENKAMP, M., \& HYDE-CLARKE, N. (2013). The use of Facebook for political commentary in South Africa. Telematics and Informatics. doi.org/10.1016/j.tele.2012.10.002

VACCARI, C., \& NIELSEN, R. K. (2013). What drives politicians' online popularity? An analysis of the 2010 US midterm elections. Journal of Information Technology \& Politics, 10(2), 208-222. doi:10.1080/19331681.2012.758072

WOJCIESZAK, M. E., \& MUTZ, D. C. (2009). Online groups and political discourse: Do online discussion spaces facilitate exposure to political disagreement? Journal of Communication, 59(1), 40-56. doi:10.1111/j.1460-2466.2008.01403.x 
NIELSEN, Rasmus Kleis \& VACCARI, Cristian. As pessoas curtem os politicos no facebook?

Não mesmo! A comunicação direta em larga escala entre candidatos e eleitores como um fenômeno outlier

ZALLER, J. (2003). A new standard of news quality: Burglar alarms for the monitorial citizen. Political Communication, 20(2), 109-130. doi:10.1080/10584600390211136 